\title{
The Doctor-Comatose Patient Relationship and Decision- Making in the Intensive Care Unit
}

\author{
Marek Petrů \\ University of Ostrava
}

\begin{abstract}
Cognitive science has not yet revealed the mystery of the mind, the principle and the origin of consciousness. We cannot determine with certainty whether a particular being has consciousness and is someone, or lacks it and is something. The doctor at the patient's bedside in the neurological intensive care unit has to, for example, make decisions even in this situation of uncertainty. In this study, using the example of clinical diagnostics and therapy of quantitative disorders of consciousness, the author examines the extent to which this ignorance represents a barrier preventing the neurologist from taking on the unambiguous decision about the therapy. He claims that the doctor in the intensive care unit is in a similar extreme situation, the solution of which requires analogous virtues that Tzvetan Todorov identified among prisoners in Nazi concentration camps.
\end{abstract}

\section{Keywords}

Consciousness, Disorders of Consciousness, Doctor-Patient Relationship, Virtue Ethics, Medical Ethics, Neuroethics

\section{Contact address}

Doc. Mgr. Marek Petrů, Ph.D., Department of Philosophy, Faculty of Arts, University of Ostrava, Reální 5, 701 03, Ostrava, Czech Republic; e-mail: Marek.Petru@osu.cz

\section{Acknowledgment}

This paper was supported by the project Antropocentrismus v etice (SGS01/FF/2020) of University of Ostrava. 
In 1637, dissatisfied with the state of knowledge hitherto, René Descartes published his work Discourse on the Method, the quintessence of his philosophy. In this he attempted to outline the rules of scientific investigation, which would bring future generations knowledge of the fundamental principles on how the world functions, meaning both the external and internal world, thus enabling a Man to live a good and righteous life. Descartes was acutely aware, however, that such a triumphant science, the foundations of which he intended to lay, was not yet available, and that it was nevertheless necessary to live and govern our lives even if on the basis of imperfect and erroneous knowledge. As a result, he proposed the rules of a provisional morality, which he would abide by and which would enable him to make plans and take decisions even in an unknown situation. ${ }^{1}$

In 2006, the American psychiatrist Steven Rose named the twenty first century the "century of the brain". ${ }^{2}$ Despite the immense knowledge that Descartes' new science produced, the relationship between the brain and mind remains just as opaque as it was in the seventeenth century. Provisional morality, at least in the field of neuroscience, is still needed.

In this paper, I focus on the practical and moral difficulties which accompany the everyday decision-making process of clinical neurologists concerning the method of therapy for non-communicative patients with disorders of consciousness in intensive care units. Just as in the case of Descartes, clinical neurologists today also have to abide by a kind of provisional and situational moral code, and decide upon the life and death of their patients in a situation of unconsciousness, whilst anxiously awaiting the results of a new science which could place these ambivalent moral rules on firm foundations.

I will argue that until our knowledge of how the brain generates consciousness and when it disappears improves, neurologists who determine the level of therapy for patients in comatose and postcomatose states find themselves in a situation that Tzvetan Todorov has defined as "extreme." I suggest that clinicians, when deciding in this situation of uncertainty and risk about the therapy, can be inspired by the ethics of virtues, and in particular the virtues that Todorov observed and deduced from the behaviour of some prisoners in the concentration camps of various totalitarian regimes.

\section{Differential diagnostics of post-comatose states}

One of the most important requirements in treating patients with serious brain injuries, accompanied by disorders of consciousness, is to evaluate the degree of their capacity for

\footnotetext{
1 "So as not to be indecisive in my actions during the time when reason obliged me to be so in my judgements, and in order to live as well as I could during this time, I formed for myself a provisional moral code, consisting of just three or four maxims." Descartes, Rozprava o metodè (Discourse on the Method), 20. These maxims were as follows: to obey the laws and customs of his country, to be as firm and decisive in his actions as he could once he had adopted them, and finally, in the manner of the stoics, to try always to master himself rather than fortune, and change his desires rather than changing how things stood in the world.

${ }^{2}$ Rose, The 21st-Century Brain: Explaining, Mending and Manipulating the Mind.

3 Todorov, T.: V mezni situaci (Facing the Extreme), 60.
} 
residual awareness of themselves and their surroundings, and on the basis of this to stipulate the intensity and method of therapy. There is a difference between a situation in which you assume that the body lying before you is a living and breathing being, but without consciousness and the ability to experience and suffer subjectively, and a situation in which you have concerns that the non-communicative patient is capable of perception and suffers not only physical pain. A necessary condition of the possibility of having rights is to be a moral subject, a person - i.e. to have consciousness. If manifestations of consciousness and the ability to establish a relationship with one's surroundings are irretrievably lost (as in the case of diagnosed brain death), that person, including his/her body, is excluded from the moral community, ceases to have the right to costly healthcare and becomes an object. In the majority of cases, the doctor then legally decides to terminate therapy. However, not only the doctor's empathy, which ensues from his/her position as the second person (within the doctor-patient relationship), but also the methods of objective diagnostics, mostly based on behavioural evidence, frequently fail in these cases. ${ }^{4}$

The difficulty of the situation can be illustrated in problems with differential diagnostics of post-comatose states. People may fall into a coma due to a number of causes (traumatic, metabolic, toxic...). Comatose patients cannot be brought to consciousness, have closed eyes, no alternation of the cycle of sleep and wakefulness, and do not respond to any sensory or cognitive stimuli. They retain, however, certain basic reflexes (for example, reaction to painful stimulus), based upon which the depth of the coma is assessed. Approximately $50 \%$ of comatose states end with the death of the patient, in the majority of cases as a consequence of a declared or undeclared termination of therapy. ${ }^{5}$

In a certain number of cases, instead of rapidly regaining consciousness or conversely dying, the comatose patient passes into a kind of intermediary state between life and death, which is most commonly referred to as a vegetative state (VS - the terms coma vigile or apallic syndrome are also sometimes used). A vegetative state is therefore defined as a clinical condition of complete loss of consciousness of one's self and surroundings accompanied by a cycle of sleep - wakefulness and retained complete or partial autonomous function of the hypothalamus and brain stem. ${ }^{6}$ A patient in a vegetative state is capable of breathing unaided, and can be detached from a respirator, but does not manifest any sign of awareness of his/her surroundings. The patient gives an impression of wakefulness, i.e. has open eyes, but the gaze does not fix on objects, and is either torpid or sporadically wanders without the movement of the eyeball being induced by any stimulus. It is impossible to establish contact with the patient either by words or gestures, and it is impossible to generate any

\footnotetext{
${ }^{4}$ As certain studies indicate, the amount of patients erroneously classed within the category of a "vegetative state" with all its consequences, is alarming (approximately 40\%). Compare Childs, Mercer, Childs, Accuracy of Diagnosis of Persistent Vegetative State, 1463-1467.

${ }^{5}$ Nebudová, Neurologická diagnostika tě̌̌kých kraniocerebrálních poranění (Neurological Diagnosis of Severe Craniocerebral Injuries), 100-103.

${ }^{6}$ Doležil, Carbolová, Vegetativni stav (Vegetative State), 27-31.
} 
affective response. Only massive stimulation may occasionally cause the patient to speak without producing meaning or making an undirected movement.

If the patient is "lucky", after a certain time he/she may progress from a vegetative state into a "minimally conscious state (MCS). ${ }^{7}$ This state was defined by neurologists in 2002 as a "state of seriously impaired consciousness, within the framework of which there are minimal but clear behavioural manifestations of consciousness of the self and surroundings". ${ }^{8}$ The difference between a vegetative state and minimal consciousness therefore consists, as is evident from the name, in the presence of a minimal degree of consciousness. In a situation where it is biologically impossible to experience a person's condition in the first person, clinicians debate the behavioural criteria which enable the diagnosis of this state from the position of the third person. This represents an immensely important debate, since deciding on this diagnosis is frequently a decision on the quality of care (maximal. unexpanded or basal therapy), and is thus a decision involving life and death. If consciousness is a condition of moral subjectivity, then this concerns a decision on exclusion from the moral community, with all the attendant legal consequences. However, to date it is not clear whatsoever as to what stimuli should be used in clinical testing of the behavioural responses which would demonstrate the presence of consciousness.

One of the first manifestations of emergence from a vegetative state to a minimally conscious state is an evident effort on the part of the patient to observe a moving target. There is no consensus, however, regarding what kind of visual stimulus clinicians should use in testing. Within the framework of their study investigating the ability of visual observation in 51 post-comatose patients, for example, Vanhaudenhuyse et al. determined that more than one fifth of patients in a minimally conscious state were able to trace only a moving mirror image ${ }^{9}$ and not a moving object or person (the most frequently used stimuli in clinical tests). ${ }^{10}$

The most widely used clinical test enabling differentiation of patients in a coma or vegetative state from patients in a minimally conscious state is assessment of motor response to a command. A reproducible motor response to a command (e.g. "stick out your tongue") is understood as a perceptible sign of minimal consciousness. A positive behavioural response to a visual or verbal stimulation is a sufficient, but not necessary condition for diagnosis of a minimally conscious state! It is entirely possible that a non-responsive patient also possesses a certain degree of consciousness.

In one of the first studies of residual brain functions on a patient in a post-traumatic vegetative state, regional brain perfusion was measured using the method of positron emission tomography (PET). A story, read by the mother of the patient, generated increased

\footnotetext{
${ }^{7}$ Although some neurologists evaluate this state as "a fate worse than death". Compare Feinberg, Ferry, A Fate Worse Than Death, 128-130.

${ }^{8}$ Giacino, The Minimally Conscious State. Definition and Diagnostic Criteria, 349-353.

${ }^{9}$ It is noteworthy that psychologists developed a mirror test identifying reflexive awareness in animals as early as the 1970s. Compare Gallup, Self-recognition in Chimpanzees and Man: A Developmental and Comparative Perspective.

${ }^{10}$ Vanhaudenhuyse, Schnakers, Bredart, Assessment of Visual Pursuit in Post-comatose States. Use a Mirror, 223.
} 
activity of the temporal lobe and anterior cingulum in comparison with control non-verbal sounds. ${ }^{11}$

In another study, investigators recorded auditory evoked potentials generated by the patient's own name or other names in 15 individuals following a brain injury. ${ }^{12}$ A P300 wave $^{13}$ was recorded as a response to stimulation by the patient's own name in all patients with a diagnosis of locked-in syndrome, in all the patients in MCS and in three patients out of five in a vegetative state. The researchers concluded their study with the statement that signs of a partially retained capacity to process semantic information are present in several non-communicative patients following a brain injury. ${ }^{14}$

A scientific sensation was caused in 2006 by the report by Owen et al., who used functional magnetic resonance imaging ( $\mathrm{fMRI}$ ) to demonstrate indisputable signs of consciousness in a patient who was diagnosed according to the strictest behavioural criteria as vegetative. ${ }^{15}$ This was a twenty-three-year-old woman who had suffered a serious brain injury in a traffic accident in 2005. Upon admittance to hospital, her Glasgow coma scale reached four points. CT detected brain swelling, haemorrhage into the left lateral ventricle, a minor contusion in the left frontal lobe close to the corpus callosum, a contusion in the right frontal and in the left posterior temporal lobe. The day after admittance, the patient underwent a decompressive craniectomy, and one month later a ventriculoperitoneal shunt was inserted into the right lateral ventricle. During the five months between the injury and the fMRI examination, the patient's condition was repeatedly diagnosed on the basis of a standardised clinical evaluation as vegetative by a multi-disciplinary team. No meaningful movements of the limbs, no sign of ocular fixation for longer than five seconds, no perception of visual or auditory stimulus and no motor response to verbal command were observed.

During the fMRI examination, which took place five months after the injury, the patient was asked to try to perform one of two possible tasks: "Imaging you are playing tennis" and "Imagine that you are walking around your home". These tasks were selected because in healthy volunteers they activate extensive, reliable and well definable patterns of neuronal activity in specific areas of the brain. When the patient was asked to imagine that she was playing tennis, significant activity appeared in the supplementary motor area,

${ }^{11}$ De Jong, Regional Cerebral Blood Flow Changes Related to Affective Speech Presentation in Persistent Vegetative State, 213-216.

${ }_{12}$ Perrin, Brain Response to One's Own Name in Vegetative State, Minimally Conscious State, and Locked-in Syndrome, 562-569.

${ }^{13}$ A P300 wave is evoked potential generated by the brain in connection with discriminating or decisionmaking processes. Compare Kremláček, Kuba, Objektivni hodnoceni kognitivnich funkci pomoci elektrofyziologického vyšstrèni: vlna P300 a jeji vlastnosti Objective Evaluation of Cognitive Functions by Electrophysiological Examination: P300 Wave and its Properties), 20-23.

${ }_{14}$ Nevertheless, the P300 wave does not necessarily refer to conscious perception and cannot be used for the requirements of differential diagnostics between VS and MCS, since it can be recorded even during unconscious subliminal perception. Compare Brázdil, Intracerebral Event-related Potentials to Subthreshold Target Stimuli, 650-661.

${ }_{15}$ Owen, Coleman, Boly, Detecting Awareness in the Vegetative State, 1402. 
which was indistinguishable from the neuronal activity of a healthy volunteer. In contrast to this, when the patient imagined walking around her home, activity was recorded in the parahippocampal gyrus, in the posterior parietal cortex and lateral premotor cortex, again similar to the activity in healthy volunteers. The patient performed these mental activities repeatedly for a period of thirty seconds, and characteristic neuronal patterns of activity were recorded throughout the entire period. Following the command "rest", the brain also ceased to be active. Despite the diagnosis of VS, this woman evidently understood verbal commands, was capable of performing them, and was therefore indisputably aware of both herself and her surroundings. ${ }^{16}$

This report triggered a whole range of further research projects, within the framework of which the investigators attempted to determine the extent to which this patient represented a bizarre exception and the extent to which it was possible that other vegetative or comatose patients also possessed consciousness or even understood speech.

In 2007, Coleman used fMRI to examine the scope of individual linguistic abilities in an etiologically heterogeneous group of patients, of whom seven were diagnosed as vegetative, five minimally conscious and two with impaired consciousness but who had emerged from MCS. Three levels of processing auditory stimulus were evaluated. These were low, when contrast between auditory stimuli and silence was measured, medium, in which contrast between verbal stimuli and unintelligible noise was evaluated, and high, when contrast was measured in responses of the brain to words which are semantically ambiguous (There were "dates" and "pears" in the fruit bowl) versus uncomplicated words (There was "beer" and "cider" on the kitchen shelf). In accordance with expectation, both patients with impaired consciousness manifested a retained capacity for language processing on all three levels. Despite, however, the established differential diagnostic criteria defining a vegetative state and minimally conscious state, some patients with VS and MCS did not manifest any significant response to auditory stimuli, whereas others (including two patients in a vegetative state!) showed evidence of a high level of processing semantic information, which was similar to that of healthy volunteers. This research therefore indicated amongst other factors that certain patients who meet the diagnostic criteria for a vegetative state may in fact have an unimpaired neuronal system, enabling the comprehension of language. ${ }^{17}$

Di et al. (2007) used fMRI to examine residual brain activity generated by the patient's own name, spoken by a close relative. Seven patients in VS and four in MCS were studied. In two patients in a vegetative state, it was impossible to demonstrate any significant brain activity. Increased activity in the primary auditory cortex appeared as a response in three patients in VS. With the remaining two patients in VS and all the patients in MCS, activity was demonstrated not only of the primary auditory cortex, but also of the supplementary auditory regions in the temporal cortex - i.e. hierarchically higher regions. These two vegetative patients with extensive cerebral activity progressed to behaviourally diagnosable minimal consciousness three months after testing (they were able to raise their arm upon

${ }^{16}$ Owen, Coleman, Using Neuroimaging to Detect Awareness in Disorders of Consciousness, 147-157.

${ }^{17}$ Coleman, Do Vegetative Patients Retain Aspects of Language Comprehension: Evidence from fMRI, 2492-2507. 
command). The condition of the other vegetative patients remained unchanged. The authors of the study conclude that cerebral response to one's own name spoken by a close relative, measured using fMRI, may be a useful tool for pre-clinical differentiation between purely vegetative patients and patients who probably have behaviourally undetectably minimal consciousness and whose condition will soon develop into an image of MCS.

A far simpler, clinically more practicable and cheaper method was proposed by Bekinschtein et al., who investigated the capacity to obey a command for a motor reaction ("move your hand") with the help of EMG on eight patients diagnosed as vegetative with a retained response to auditory evoked potentials and retained response to a nociceptive stimulus (withdrawal reflex) and on two patients in MCS. ${ }^{18}$ In both MCS patients and one vegetative patient, distinct above-threshold changes in the EMG signal were demonstrated as a response to the verbal command "move your hand". The patient evidently understood the command, since he performed the task repeatedly over the required time of thirty seconds, whereas no changes of the EMG signal appeared following the command "don't move". This patient, clinically diagnosed as vegetative, was therefore indisputably conscious.

The outcome of these studies is clear. Many (although not all) vegetative patients manifest retained "islands" of the functional pallium or neocortex, residual phatic abilities and basal consciousness. They therefore cannot be declared impercipient, let alone neocortically dead. Another challenge for researchers is to adjust the display methods so that they enable patients with disorders of consciousness to communicate their feelings and desires by means of a computer interface. ${ }^{19}$

Nevertheless, the problem goes deeper. A positive neuronal response to visual or verbal stimulation is a sufficient, but not necessary condition for the diagnosis of a minimally conscious state! Our ability to decide unequivocally as to whether a patient is conscious and thus has needs also does not depend on whether the patient is actually conscious, but on whether he/she has understood our question and is capable of responding to it. Some patients in a vegetative state in all probability suffer from global aphasia, and are incapable of responding to any linguistic command. Despite this, however, they may still be in possession of behaviourally and neuronally undetectable consciousness!

In the 1950s, the British mathematician Alan Turing designed his famous test to identify any entity of human intelligence. ${ }^{20}$ The Turing test, based on behavioural evidence, fails, however, on patients with disorders of consciousness. Even if these people are far from being able to converse fluently on diverse themes, no one would want to deny their capacity for human thought (at least in residual form) and the human rights that ensue from this - for example the right to costly medical care. And since, for several other reasons, research into thought and consciousness based on methodologies of the third person has been demonstrated to be inadequate, cognitive scientists have attempted to construct a

\footnotetext{
${ }^{18}$ Bekinschtein, Coleman, Niklison, Can Electromyography Objectively Detect Voluntary Movement in Disorders of Consciousness?, 826-8.

${ }^{19}$ Stins, Laureys, Thought Translation, Tennis and Turing Tests in the Vegetative State, 361-362.

${ }^{20}$ Turing, Počitacie stroje a inteligencia (Computing Machinery and Intelligence).
} 
rigorous methodology of research into consciousness in the first person since the 1990s. The challenge facing today's science of thought and applied ethics resides in the need to construct a new, non-reductionist theory of mental phenomena, and to this end to develop a new and broadly acceptable method of research into mental states which are accessible principally only in the first person. The first attempts to construct such a methodology are heterophenomenology and neurophenomenology. ${ }^{21}$

For clinical purposes, however, these initial attempts on the part of cognitive scientists are barely usable. Clinical doctors are not concerned first and foremost with understanding the functional principles of human thought, but rather with understanding the requirements and experiences of their patients. As a result, following in a long and distinguished tradition of medical experimentation, they ever more frequently cause disorders of consciousness in themselves, ${ }^{22}$ with the aim of determining how their patients may feel and what they perceive, and what the neuronal correlates are during these experiences, which could enable an identification of these feelings in non-communicative subjects.

An example may be the experiment conducted by Matthew H. Davis et al. ${ }^{23}$ These researchers sedated volunteers with propofol, a substance used in anaesthesia, and examined their ability to understand verbal language. Prior to this, however, they used functional magnetic resonance imaging to identify the areas of the brain that are responsible for processing semantic information. On the basis of a comparison of the brain's response to heard speech and non-verbal sound, and a subsequent comparison of the neuronal response to an unambiguous sentence and a sentence which contained ambiguous expressions and homonyms, they differentiated areas of perceptual and semantic processing of verbal information. In this they succeeded in demonstrating that the lower parts of both frontal lobes and the lower-posterior region of the left temporal lobe play the largest role in the comprehension of language (semantic processes). They subsequently placed the volunteers under three levels of sedation (a. entirely awake, b. mildly sedated - retarded and inadequate conversation, c. completely sedated - without response to verbal stimulation, although possible to awaken with a strong stimulus) and again examined the response of the brain to the subjective experience of the probands to these acoustic verbal and non-verbal stimuli. The result was relatively surprising: whereas the perceptual regions specifically responding to spoken language were active even in the state of deep sedation, the semantic regions no longer responded even under mild sedation. The researchers thus demonstrated that although basal consciousness remains present, comprehension of language may be deficient under only slight alteration of neuronal functions. This confirmed the suspicion that patients with disorders of consciousness may have subjective experiences without being

${ }^{21}$ Petrů, Fyziologie mysli (Physiology of the Mind), 300-308.

${ }^{22}$ see Glaser, Dramatická medicina (Dramatic Medicine) or Roubíček, Experimentální psychózy (Experimental Psychosis).

${ }^{23}$ Davis, Dissociating Speech Perception and Comprehension at Reduced Levels of Awareness: an fMRI Study with Graded Propofol Sedation, 16032-7. 
capable of responding to any semantic information and therefore communicating in any manner or understanding anything symbolic.

\section{Virtues in the intensive care unit}

"Tout comprendre c'est tout pardonner", pronounces a dictum of opaque origin. We wish to understand everything not so much in order to be able to pardon everything, but rather in order to survive and remain healthy in an inhospitable world. According to René Descartes, this is the chief purpose of all the sciences. If science promises to make us "lords and masters of nature", Descartes was primarily referring to mastery of the nature within ourselves. Science is important and desirable "not only for the invention of an infinity of devices that would enable one to enjoy trouble-free the fruits of the earth and all the goods found there, but also principally for the maintenance of health, which unquestionably is the first good and the foundation of all the other goods of this life, for even the mind depends so greatly on the temperament and the disposition of the organs of the body, that, if it is possible to find some means to render men generally more wise and more adroit than they have been up until now, I believe that one should look for it in medicine." ${ }^{2}$

Unfortunately, we are no more wise or adroit at present than Descartes' contemporaries. Not only is it the case that the invention of "an infinity of devices" has produced unintended consequences, as a result of which we often gain little satisfaction from their utility, but in the sphere of health we also are not as adroit as we would wish to be. With the exception of a number of indisputable successes (the discovery of antibiotics, insulin, anaesthesia, improvement of surgical techniques...), a range of fields of medicine, in particular those relating to the human mind, have not advanced greatly in terms of their practical consequences.

Until further generations of scientists devise more accomplished methods of investigation of the mind, then a whole range of questions remain unanswered. The main question also remains unanswered: what justifies us in attributing to (or conversely denying) patients with disorders of consciousness, who lack any means of communication, at least basal consciousness - the essential condition for the possibility to have rights? And how should we treat these patients? The moral decision as to whether to attempt maximum therapy on these patients, which in these cases is in all probability an exercise in futility, or whether to leave them to die either more quickly (basal therapy) or slowly (unexpanded therapy), remains an arduous moral burden for the attending physician, which contemporary science is as yet unable to remove.

I dare say that in this situation, neither utilitarian nor deontological ethics are applicable in intensive care units, but only the ethics of virtues. ${ }^{25}$ Although the ethics of

${ }^{24}$ Descartes, Rozprava o metodé (Discourse on the Method), 45.

${ }^{25}$ Hursthouse, Rosalind, Pettigrove, Glen, Virtue Ethics, URL $=<$ https://plato.stanford.edu/archives/ win2018/entries/ethics-virtue/>. 
virtues is fraught with many problems, such as its inability to codify specific standards and clear guidelines for action, these limitations can become an advantage in a situation of uncertainty and risk.

My personal experience with neurological intensive care units has convinced me that these places and the events that take place in these places are "extreme". Extreme in the sense defined by Tzvetan Todorov, himself inspired by Bruno Bettelheim, in the book "Face a l'extreme". Extreme is any situation where we are confronted with death, the limit of all things, and therefore of life. The extreme situation appears not only in the concentration camps that Todorov was most interested in, but wherever in the face of death he "reveals the truth of ordinary situations." ${ }^{26}$ An extreme situation is a moment of anxiety and despair, when the individual has to not only act on his own, but also risk the life or property of himself or his loved ones.

Through the magnifying glass of the concentration camp, Todorov saw many naked human vices and virtues. Two stood out the most, however, dignity and care. I also came across many doctors standing at a patient's bedside in an intensive care unit.

Todorov understands dignity as "the intact harmony of internal criteria and external behaviour", as "the ability to subject our deeds to criteria which we have internally accepted as our own." ${ }^{27}$ So dignity is not something we are intrinsically endowed with, but something we must constantly fight for it with our actions..., and we can therefore easily lose it. In a situation of extreme oppression, when one no longer has any choice, the minimum dignity consists in stepping out of one's own decision towards death, one's own or another's, which was intended for one.

Dignity is therefore not only fragile, but without the latter virtue it can also be perverted. After all, even the orthodox Nazis acted according to their convictions. For it to be desirable, dignity has to be accompanied by care. According to Todorov, a carer is the one who allows his goodness to take precedence over "duty" ${ }^{28}$ Caring is not the same virtue as solidarity, which unites the members of a certain group, nor the same as charity, which, on the contrary, turns out to be a kind of duty to all. The goal of care is an individual, an individual who cannot rely on receiving my care automatically, an individual whose blind fate has brought me to me and whose fate is a challenge to me and connects with mine. Finally, care is not a sacrifice. A sacrifice assumes that a person is giving up something that is dear to him, that he voluntarily renounces something with pain - for example, for the feeling of fulfilling an obligation. In contrast, care is a reward in itself. "Taking care of someone does not mean that I sacrifice my time and my strength to him, but that I dedicate them to him and bring me pleasure". ${ }^{29}$ Sacrifice is a glorification of death, care does not make sense outside life.

\footnotetext{
26 Todorov, V mezni situaci (Facing the Extreme), 313.

${ }^{27}$ Ibid, 77.

${ }^{28}$ Ibid, 83.

${ }^{29}$ Ibid, 92.
} 
The limits of contemporary science, at least that of the mind, do not represent a principally insurmountable obstacle for ethically based clinical work. The limits of contemporary science are rather a front line on which a battle against superstition, ignorance and prejudice is fought, a front line on which the new standards are tested.

The combat strategy on this front, where the enemy is disease and death, may be the ethics of virtues, specifically the virtues of a person (medical doctor) in an extreme situation. At a time when science is silent and clear criteria for action are not available, virtues such as dignity or care, virtues that often stand by in everyday life, can speak loudly. They bloom in the fruitful tension between legality and legitimacy and feed on what Aristotle called epeikeia, in other words, the ability to break the law in the name of the higher good. ${ }^{30}$

What particular implications does this have for a particular treatment of a particular patient whose consciousness of question and dignity (in the sense defined above) is lost? How does this answer the question of whether costly treatment should continue or whether therapy should be discontinued or minimised? A particular doctor's decision about a particular patient always painfully re-evokes the need to update the virtue of the doctor's dignity, i.e. the power to act on his own experience, conviction and faith, but corrected by the virtue of care, which forces the doctor to risk that he rather than the patient will bear the negative consequences of his decision.

In conclusion, I can do nothing else but quote Jean Hamburger, the founder of the first intensive care unit in France, who says of the fate of a doctor: "Man's destiny is to play the gods, for man is the only living being who sets his own laws; for medicine, which is a passion to heal, is at the same time a passion to resist death; for kings and warriors are still toying with destiny and balancing on the edge; for it seems to me that the greatness of man lies precisely in the possibility of denying the natural sequence of events and blind destiny." 31 The possibility of choosing the way of dying is a sign of human dignity.

\section{Bibliography}

Tristan A. Bekinschtein, Martin R. Coleman, Jorge Niklison, et al., "Can electromyography objectively detect voluntary movement in disorders of consciousness?," Journal of Neurology, Neurosurgery and Psychiatry (2008); 79:826-8, DOI: 10.1136/jnnp.2007.142216.

Milan Brázdil, et al., "Intracerebral event-related potentials to subthreshold target stimuli," Clin Neurophysiol. (2001);112:650-661, DOI: 10.1016/S1388-2457(01)00463-1.

Martin R. Coleman, Adrian M. Owen, "Functional Neuroimaging of Disorders of Consiousness," International Anestesiology Clinics. (2008), 46/3.147-157, DOI: 10.1097/AIA.0B013E318181ADCC.

Martin R. Coleman, et al., "Do vegetative patiens retain aspects of language comprehension: evidence from fMRI,P Brain. (2007); 130:2492-2507.

${ }^{30}$ Sinha, Wiedmann, Die bedeutung der epikie bei Aristoteles für das ärztliche Handeln (The Meaning of Aristoteles' Epikeia for Medical Treatment), 105-112.

${ }^{31}$ Hamburger, L'Aventure humaine (Human Adventure), 54. 
Matthew H. Davis, Martin R. Coleman, Anthony R. Absalom, Jennifer M. Rodd, Ingrid S. Johnsrude, Basil F. Matta, Adrian M. Owen, and David K. Menon, "Dissociating speech perception and comprehension at reduced levels of awareness: an fMRI study with graded propofol sedation," Proc Nat Acad Sci, (2007), 104, 16032-7. DOI: 10.1073/pnas.0701309104

Bauke M. De Jong, et al, "Regional cerebral blood flow changes related to affective speech presentation in persistent vegeative state,” Clin Neurol Neurosurg. (1997);99:213-216.

René Descartes, Rozprava o metodě, Svoboda, Praha 1992.

Haibo Di, et al: "Cerebral response to patient's own name in the vegetative and minimally conscious states," Neurology (2007);68:895-899. DOI: 10.1212/01.wnl.0000285428.34178.bc

David Doležil, Kamila Carbolová, “Vegetativní stav (Apalický syndrom),” Neurologie pro praxi, (2007), 1, 27-31.

William Feinberg, Peggy C. Ferry, “A Fate Worse Than Death,” AJDC, Vol 138, (1984), 128-130.

Gordon G. Gallup, G. G., Self-recognition in chimpanzees and man: A developmental and comparative perspective, New York: Plenum Press 1979.

Joseph T. Giacino, et al, “The minimally conscious state. Definition and diagnostic criteria," Neurology (2002), 58:349-353. DOI: https://doi.org/10.1212/WNL.58.3.349

Hugo Glaser, Dramatická medicina; Mladá fronta, Praha 1996.

Rosalind Hursthouse and Glen Pettigrove, „Virtue Ethics“, The Stanford Encyclopedia of Philosophy (Winter 2018 Edition), Edward N. Zalta (ed.), URL = <https://plato.stanford.edu/archives/win2018/entries/ ethics-virtue/>.

N. L. Childs, Wald N. Mercer, Helen W. Childs, "Accuracy of diagnosis of persistent vegetative state. Neurology," (1993),43:1463-1467.

Jan Kremláček, Miroslav Kuba, “Objektivní hodnocení kognitivních funkcí pomocí elektrofyziologického vyšetření: vlna P300 a její vlastnosti.” In Struny mysli, ed. Petrü, M: Montanex, Ostrava 2009.

Jaroslava Nebudová, Neurologická diagnostika těžkých kraniocerebrálních poranèní, Avicenum, Praha 1984.

Adrian M. Owen, Martin R. Coleman, Melanie Boly, et al., "Detecting awareness in the vegetative state," Science (2006); 313:1402. DOI: 10.1126/science.1130197

Adrian M. Owen, Martrin R. Coleman, "Using Neuroimaging to Detect Awareness in Disorders of Consciousness," Funcional Neurology (2008);23(4).

Fabien Perrin, et al, "Brain Response to One’s Own Name in Vegetative State, Minimally Conscious State, and Locked-in Syndrome," Arch Neurol. Vol 63, 3/(2006):562-569.

Marek Petrů, Fyziologie mysli, Triton, Praha 2007.

Vilaynur S. Ramachandran, William Hirstein, “Three Laws of Qualia”. In. Gallagher, S., Shear, J. (Eds.).: Models of the self. Imprint Academic 1999.

Steven Rose, The 21st-Century Brain: Explaining, Mending and Manipulating the Mind; Vintage, 2006.

Jiří Roubíček, Experimentální psychózy, Státní zdravotnické nakladatelství, Praha 1960.

Anil-Martin Sinha, Franz Wiedmann, „Die bedeutung der epikie bei Aristoteles für das ärztliche Handeln,“ Wurzbg Medizinhist Mitt. (2003);22:105-112. 
John F. Stins, Steven Laureys, “Thougt translation, tenis and Turing tests in the vegetative state," Phenom Cgn Sci (2009) 8:361-362.

Tzvetan Todorov, Vmezni situaci, Mladá fronta 2000.

Alan Turing, "Počítacie stroje a inteligencia”; In.: Gál, E., Kelemen, J. (pořadatelé); Myseĺ, telo, stroj; Bradlo 1992.

Audrey Vanhaudenhuyse, Caroline Schnakers, Serge Bredart, Steve Laureys, "Assessment of visual pursuit in post- comatose states. Use a mirror," J Neurol Neurosurg Psychiatry (2008); 79:223. DOI: 10.1136/ jnnp.2007.121624 